Tropical Journal of Pharmaceutical Research October 2021; 20 (10): 2035-2041

ISSN: $1596-5996$ (print); 1596-9827 (electronic) (C) Pharmacotherapy Group, Faculty of Pharmacy, University of Benin, Benin City, 300001 Nigeria.

\title{
Lipoic acid inhibits nerve cell apoptosis in rats with Parkinson's disease via Erk signaling pathway
}

\author{
Xin $\mathrm{Li}^{1 *}$, Wei $\mathrm{Li}^{2}$, Weigang $\mathrm{Li}^{3}$, Jian Zhang ${ }^{3}$ \\ ${ }^{1}$ Department of Psychology, ${ }^{2}$ Department of Cardiology, ${ }^{3}$ Department of Radiology, Taizhou People's Hospital, Taizhou, China \\ *For correspondence: Email: leexintzh@sina.com; Tel: +86-018752600119
}

Sent for review: 30 July 2021

Revised accepted: 26 September 2021

\begin{abstract}
Purpose: To investigate the effect of lipoic acid on nerve cell apoptosis in rats with Parkinson's disease via the extracellular signal-regulated kinase (ERK) signaling pathway.

Methods: A total of 36 rats were randomly divided into normal group $(n=12)$, Parkinson's disease model group $(n=12)$ and lipoic acid group $(n=12)$. The neuronal morphology was examined by means of Nissl staining, while cell apoptosis was assessed by terminal deoxynucleotidyl transferase-mediated dUTP nick end labeling (TUNEL) assay.

Results: The neurons were severely damaged in model group, while neuronal morphology and structure were ameliorated in lipoic acid group when compared with those in model group. The $p$-ERK was lowered significantly $(p<0.05)$ in model group and lipoic acid group compared with that in normal group. Levels of mRNA, caspase-3 and Bax increased significantly, while Bcl-2 decreased in model group and lipoic acid group when compared with those in normal group $(p<0.05)$. Lipoic acid treatment significantly reduced mRNA expression of caspase-3 and Bax, but increased Bcl-2 compared with model group. Furthermore, ELISA results indicate that model and lipoic acid groups exhibited raised caspase-3 and Bax but significantly reduced Bcl-2 levels, compared with normal group. The results also showed that the apoptosis was higher in the other two groups than in normal group; on the other hand, it was significantly lower in lipoic acid group than in model group $(p<0.05)$.

Conclusion: Lipoic acid inhibits nerve cell apoptosis in rats with Parkinson's disease by up-regulating ERK signaling pathway. Therefore, lipoic acid is a potential neuroprotective agent for the management of Parkinson's disease.
\end{abstract}

Keywords: Parkinson's disease, Lipoic acid, Apoptosis, ERK signaling, Inflammation

\begin{abstract}
This is an Open Access article that uses a funding model which does not charge readers or their institutions for access and distributed under the terms of the Creative Commons Attribution License (http://creativecommons.org/licenses/by/4.0) and the Budapest Open Access Initiative (http://www.budapestopenaccessinitiative.org/read), which permit unrestricted use, distribution, and reproduction in any medium, provided the original work is properly credited.

Tropical Journal of Pharmaceutical Research is indexed by Science Citation Index (SciSearch), Scopus, International Pharmaceutical Abstract, Chemical Abstracts, Embase, Index Copernicus, EBSCO, African Index Medicus, JournalSeek, Journal Citation Reports/Science Edition, Directory of Open Access Journals (DOAJ), African Journal Online, Bioline International, Open-J-Gate and Pharmacy Abstracts
\end{abstract}

\section{INTRODUCTION}

Parkinson's disease, a fairly common neurological disease in clinics at present, frequently occurs in the elderly people. It is characterized by muscle stiffness and uncontrollable tremor, which mainly impair the autonomic motor function and results in limb motor dysfunction in patients [1,2]. Studies [3,4] have illustrated that nervous system injury, especially the extrapyramidal injury in the central nervous system, is the major pathological damage caused by Parkinson's disease [3,4]. There has been no satisfactory therapeutic method for Parkinson's disease so far, and 
clinical treatment of the disease is always a worldwide difficulty.

Existing studies [5-7] have demonstrated that the destruction of dopaminergic neurons in the central nervous system is the main pathological mechanism of Parkinson's disease, which is closely associated with muscle stiffness, tremor and autonomic dysfunction in patients. Further investigations $[8,9]$ have shown that in the pathological process of Parkinson's disease, massive nerve cell apoptosis is an important means of destroying the dopaminergic neurons, so it is considered as one of the major pathological responses of the disease. As a result, intervening in excess nerve cell apoptosis during Parkinson's disease is an effective idea and method of researching and treating Parkinson's disease.

It has been proven that lipoic acid, a substance extracted from the liver of a pig, has favorable anti-oxidant response, anti-inflammatory and neuroprotective effects, but its in-depth mechanism remains unclear [10].

This research aims to explore the effect of lipoic acid on the nerve cell apoptosis in rats with Parkinson's disease through the extracellular signal-regulated kinase (ERK) signaling pathway.

\section{EXPERIMENTAL}

\section{Laboratory animals and grouping}

A total of 36 Sprague-Dawley rats weighing 200 $\pm 20 \mathrm{~g}$ were purchased from Shanghai SLAC Laboratory Animal Co., Ltd. [license No.: SCXK (Shanghai) 2014-0003], the rats were divided into normal group $(n=12)$, model group $(n=12)$ and lipoic acid group $(n=12)$ using a random number table. This study was approved by the Animal Ethics Committee of Taizhou People's Hospital Animal Center (17-TZ-0012-AC-592).

\section{Reagents and equipment}

Lipoic acid injection was provided by Justawore Pharmaceutical Co. Ltd (Tianjin, China). Antiphosphorylated ( $p$ )-ERK primary antibody and secondary antibody were offered by Abcam (Cambridge, MA, USA). Enzyme-linked immunosorbent assay (ELISA) kits and terminal deoxynucleotidyl transferase-mediated dUTP nick end labeling (TUNEL) apoptosis assay kits were bought from Boster (Wuhan, China). Quantitative polymerase chain reaction (qPCR)related kits were purchased from Vazyme (Nanjing, China), and a DMI 4000B/DFC425C light microscope was bought from Leica (Wetzlar,
Germany). An ABI 7500 fluorescence qPCR instrument was provided by $A B I$ (Foster City, CA, USA), while Image-Pro image analysis system was offered by BIO (Hercules, CA, USA).

\section{Model establishment}

A rat model of Parkinson's disease was established by injecting rotenone-sunflower oil emulsion into the rats. Specifically, the rotenonesunflower oil emulsion was injected subcutaneously $(0.01 \mathrm{~mL} / \mathrm{kg})$ at the neck of the rats daily. The rat model of Parkinson's disease was successfully prepared after 2 consecutive weeks of injection.

\section{Treatments}

The rats in normal group did not receive any treatment, and those in model group and lipoic acid group were applied to prepare the models of Parkinson's disease according to the aforementioned methods. After operation, the rats in the two groups were intraperitoneally injected with an equal volume of normal saline and lipoic acid injection (50 mg/kg), respectively, every day. Finally, specimens were obtained from each group 14 weeks after operation.

\section{Specimen acquisition}

After successful anesthesia using peritoneal administration of pentobarbital sodium at a dose of $150 \mathrm{mg} / \mathrm{kg}$, the brain tissues were collected from 6 rats for each group through perfusionfixation with paraformaldehyde. The brain tissues were fixed in $4 \%$ paraformaldehyde at $4^{\circ} \mathrm{C}$ for 48 h. Then the brain tissues were made into paraffin-embedded sections for Nissl staining and TUNEL assay. Subsequently, specimens of brain tissues were collected from the remaining 6 rats in each group, and placed in EP tubes for Western blotting (WB) assay, ELISA and qPCR assays.

\section{Nissl staining}

The tissues embedded in paraffin in advance were sliced into $5 \mu \mathrm{m}$-thick sections, followed by spreading in warm water at $42{ }^{\circ} \mathrm{C}$, collection and baking. Therefore, the paraffin-embedded sections were prepared. Then the paraffinembedded sections were soaked in xylene solution and gradient alcohol for routine deparaffinization until rehydration. Finally, the sections were subjected to sequential staining and color separation in sequence according to the procedures in Nissl staining kits, and they were mounted after good staining was observed. 


\section{Western blot assay}

The lysis buffer was added into the cryopreserved brain tissues for $1 \mathrm{~h}$ of ice bath, then the tissues were centrifuged at $14,000 \mathrm{~g}$ in a centrifuge for $10 \mathrm{~min}$, and the proteins were quantified using bicinchoninic acid (BCA) method (Pierce, Rockford, IL, USA). Next, the absorbance and standard curve of the proteins were obtained through a microplate reader, based on which the protein concentration in tissues was calculated. Subsequently, the proteins in tissue specimens were denatured and separated via sodium dodecyl sulphatepolyacrylamide gel electrophoresis (SDS-PAGE), during which the position of the marker proteins was observed, and the electrophoresis was stopped when the Marker proteins reached the bottom of the glass plate in a straight line.

The proteins were transferred onto a polyvinylidene fluoride (PVDF) membrane (Millipore, Billerica, MA, USA) and reacted with blocking buffer for $1.5 \mathrm{~h}$. After that, anti-p-ERK primary antibody (1:1000) and secondary antibody (1:1000) were added in sequence. Finally, immuno-reactive bands were visualized by enhanced chemiluminescence (ECL) detection kit (Amersham Biosciences, Foster City, CA, USA).

\section{Quantitative reverse transcription polymerase chain reaction (qRT-PCR)}

Fresh brain tissues were added into the ribonucleic acid (RNA) extraction reagent to extract the total RNAs the extracted total RNAs were reversely transcribed into complementary deoxyribonucleic acids (cDNAs) using reverse transcription kit and a designed reaction system $(20 \mu \mathrm{L})$ under the following conditions: reaction at $53{ }^{\circ} \mathrm{C}$ for $5 \mathrm{~min}$, pre-denaturation at $95^{\circ} \mathrm{C}$ for $10 \mathrm{~min}$, denaturation at $95{ }^{\circ} \mathrm{C}$ for $10 \mathrm{~s}$ and annealing at $62^{\circ} \mathrm{C}$ for $30 \mathrm{sec}$ for 35 cycles. The relative gene level was calculated by $2-\Delta \Delta \mathrm{Ct}$ method. The primer sequences are shown in Table 1.
Enzyme-linked immunosorbent assay (ELISA)

The brain tissues were ground into minced material. Based on the instructions of the ELISA kit, samples were loaded. Biotinylated antibody working solution and enzyme conjugate working solution were added (Beyotime, Shanghai, China). Finally, the plate was washed, and the tissues were determined using the microplate reader at $450 \mathrm{~nm}$.

\section{TUNNEL apoptosis assay}

The tissues embedded in paraffin ahead were sliced into $5 \mu \mathrm{m}$-thick sections, spread in warm water at $42^{\circ} \mathrm{C}$, collected and baked, so as to prepare the paraffin-embedded sections. Then the paraffin-embedded sections were routinely deparaffinized in xylene solution and gradient alcohol until rehydration. TdT solution was added in drops for reaction in the dark for $1 \mathrm{~h}$. Then deionized water was added dropwise, and incubated for $15 \mathrm{~min}$ to terminate the reaction. After that, hydrogen peroxide was added in drops to block the activity of endogenous peroxidase, and working solution was added dropwise for $1 \mathrm{~h}$ of reaction. Finally, after rinsing, the color was developed using DAB solution added in drops, followed by rinsing and mounting for observation.

\section{Statistical analysis}

Statistical Package for Social Sciences (SPSS) 20.0 software (IBM, Armonk, NY, USA) was adopted for statistical analysis. The measurement data are expressed as mean \pm standard deviation (SD). A t-test was performed for data meeting the conditions for normal distribution and homogeneity of variance, corrected t-test was performed for those meeting normal distribution and heterogeneity of variance, and non-parametric test was utilized for those not meeting normal distribution and homogeneity of variance. The ranked data were examined by rank sum test, while the enumeration data were subjected to chi-square test.

Table 1: Primer sequences used in PCR

\begin{tabular}{ll}
\hline Name & Primer sequence \\
\hline \multirow{2}{*}{ Caspase-3 } & Forward: 5'TTGTCCCATGCTATTGGCCC3' \\
& Reverse: 5'TTGTCCCATGCTATTGGCCC3' \\
Bcl-2-associated X protein (Bax) & Forward: 5'GAGGATCCATGGACGGGTCCGGGGA3' \\
& Reverse: 5'CGCCTCGAGTCAGCCCATCTTTCTTC3' \\
B-cell lymphoma-2 (Bcl-2) & Forward: 5'TCATTCGGAAGTTTCAGAGCA3' \\
& Reverse: 5'TTGTCCCATGCTATTGGCCC3' \\
GAPDH & Forward: 5'ACGGCAAGTTCAACGGCACAG3' \\
& Reverse: 5'GAAGACGCCAGTAGACTCCACGAC3' \\
\hline
\end{tabular}




\section{RESULTS}

\section{Nissl staining results}

As shown in Figure 1 the neuronal morphology and structure were normal, with no apparent injury, and the Nissl bodies were regular in morphology and abundant in quantity in normal group. The neurons were swollen or broken, the nuclei disappeared, and there were few and broken Nissl bodies in model group. In lipoic acid group, the neurons were partially swollen, and the neuronal morphology and structure were improved compared with those in model group, with a larger number of Nissl bodies.

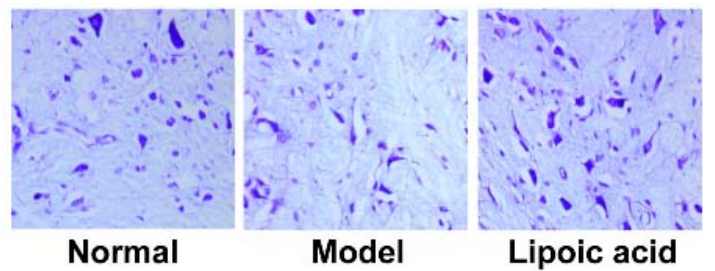

Figure 1: Nissl staining results (magnification: 400×)

\section{Expression of related protein}

The protein expression of p-ERK was high in normal group but low in model group and lipoic acid group (Figure 2 A). As shown in Figure 2 B, the relative protein expression level of $p$-ERK was lowered significantly in model group and lipoic acid group when compared with that in normal group $(p<0.05)$, but it was significantly elevated in lipoic acid group in contrast with that in model group $(p<0.05)$.

\section{Expression levels of relevant messenger RNAs (mRNAs)}

The relative mRNA expression levels of Caspase-3 and Bax were increased significantly, while that of Bcl-2 was decreased significantly in model group and lipoic acid group in comparison with those in normal group $(p<0.05)$ (Figure 3$)$. However, lipoic acid group had significantly lower relative mRNA expression levels of caspase-3 and Bax and a significantly higher relative mRNA expression level of $\mathrm{Bcl}-2$ than the model group ( $p$ $<0.05)$.

\section{Effect of lipoic acid on expressions of caspase-3, Bax and Bcl-2}

Model group and lipoic acid group exhibited significantly raised relative protein expression levels of Caspase- 3 and Bax as well as a significantly reduced relative protein expression level of Bcl-2 compared with normal group ( $p<$
0.05), while the opposite trends of the above proteins were observed between lipoic acid group and model group ( $p<0.05 \mathrm{Fi}$, Figure 4$)$.



B

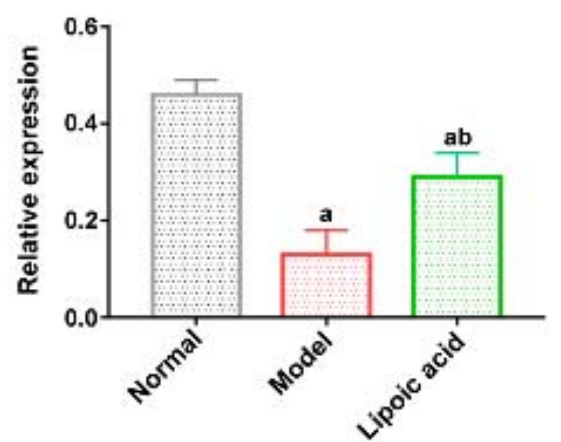

Figure 2: Expression levels of related protein. Note: (A) Bands from Western blot assay, (B) Relative protein expression level in each group. ${ }^{\text {ap }}<0.05$ vs. normal group, ${ }^{b} p<0.05$ vs. model group

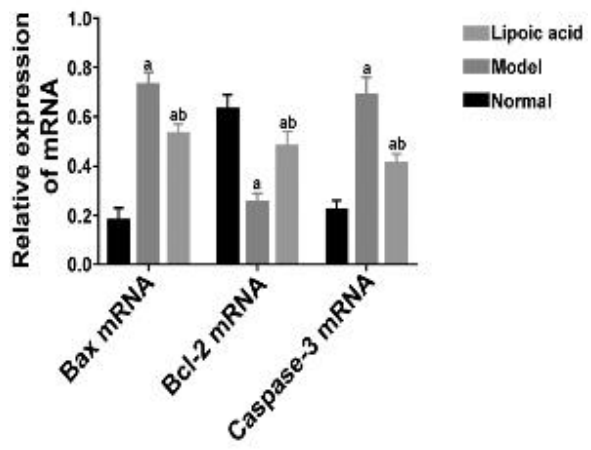

Figure 3: Relative expressions of mRNA. ${ }^{a} P<0.05$ vs. normal group, ${ }^{b} p<0.05$ vs. model group

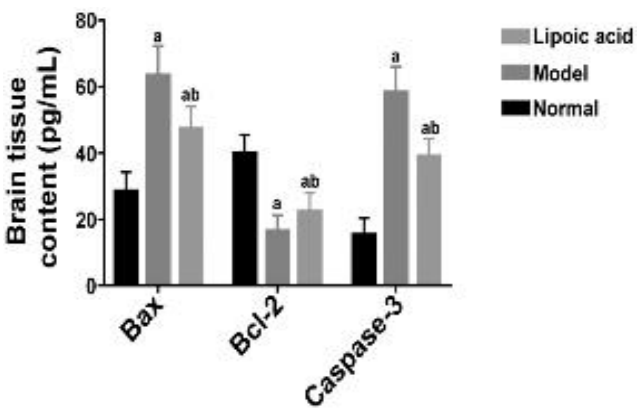

Figure 4: Effect of lipoic acid on expressions of caspase-3, Bax and Bcl-2. ${ }^{a} P<0.05$ vs. normal group, ${ }^{b} p<0.05$ vs. model group

Trop J Pharm Res, October 2021; 20(10): 2038 


\section{Effect of lipoic acid on cell apoptosis}

The apoptotic cells were dark brown. There was less cell apoptosis in normal group and more cell apoptosis in the other two groups. The apoptosis rate was significantly higher in lipoic acid and model groups than that in normal group $(p<$ 0.05 ), while it was significantly lower in lipoic acid group than that in model group $(p<0.05$, Figure $5)$.

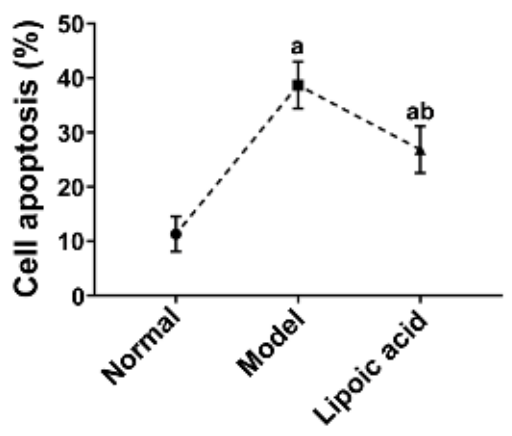

Figure 5: Effect of lipoic acid on cell apoptosis via TUNEL assay. Relative protein expression level in each group. ${ }^{a} P<0.05$ vs. normal group, ${ }^{b} p<0.05$ vs. model group

\section{DISCUSSION}

The incidence of Parkinson's disease, a relatively common neurological disease in the elderly, has a close correlation with the degenerative changes of the central nervous system of the elderly. Parkinson's disease affects mainly the autonomic motor function of the elderly patients, causing a series of clinical manifestations such as muscle stiffness, tremor and autonomic motor dysfunction in patients. Currently, it is argued that extrapyramidal injury is one of the primary pathological mechanisms of Parkinson's disease which is a neurological disease induced by degenerative changes of the central nervous system [11,12]. In particular, further studies [1315] have revealed that the pathological responses and mechanisms of Parkinson's disease are very complex, which involve multiple pathological aspects and signaling pathways, including such pathological responses as inflammation, apoptosis, necrosis and autophagy.

As an ubiquitous pathological response of central nervous system injury, nerve cell apoptosis is not only a crucial cause of degenerative changes in the central nervous system, especially the extrapyramidal system, but also one of the vital pathological causes of the onset of Parkinson's disease. Hence, nerve cell apoptosis is regarded as one of the important ways to research and treat Parkinson's disease $[16,17]$. Studies have demonstrated that during the pathogenesis of Parkinson's disease, the secretion and release of numerous inflammatory factors and cytokines triggered the apoptosis of massive nerve cells, thus aggravating extrapyramidal injury and leading to degenerative changes of the central nervous system.

The ERK signaling pathway plays a pivotal role among the physiological and pathological factors for nerve cell apoptosis. It is believed that as a crucial signaling pathway in the body, the ERK signaling pathway is involved in the pathogenesis of Parkinson's disease, and serves as an important regulator due to its vital anti-apoptotic effect.

Based on research $[18,19]$, the ERK signaling pathway can be activated under the action of pathological factors such as massive inflammatory factors, cytokines and cytotoxic amino acids. Therefore, ERK, a key molecule in the ERK signaling pathway, is phosphorylated extensively to form $p$-ERK, further regulating the transcription and translation of various downstream apoptosis-related proteins, sin order to modulate cell apoptosis. By this process, Bax, as a crucial pro-apoptotic factor, can remarkably facilitate cell apoptosis, while Bcl-2 acts as a vital anti-apoptosis factor to effectively inhibit cell apoptosis, and caspase- 3 is an important apoptosis effector capable of directly triggering cell apoptosis.

A previous study [20] indicated that the ERK signaling pathway regulates $\mathrm{Bax}, \mathrm{Bcl}-2$ and Caspase-3 prominently. In other words, it can exert a pivotal anti-apoptotic effect by downregulating the expressions of Bax and Caspase- 3 and up-regulating $\mathrm{Bcl}-2$ expression. It was also confirmed in this research that the protein expression of $p$-ERK, a key molecule of the ERK signaling pathway, was notably decreased in the brain tissues of rats with Parkinson's disease, suggesting that the ERK signaling pathway is repressed. Moreover, the expressions of proapoptotic Bax and apoptosis effector Caspase-3 were markedly raised, while that of anti-apoptotic $\mathrm{Bcl}-2$ was evidently reduced, and the apoptosis of a large number of nerve cells occurred, thus destroying the neurons.

Lipoic acid is a drug with anti-inflammatory, antioxidant and neuroprotective effects, but its related mechanism of action has not been clarified yet. It was discovered in this research that lipoic acid was able to efficaciously improve the neuronal morphology in the brain tissues of rats with Parkinson's disease, further validating the neuroprotective effect of lipoic acid. In order 
to ascertain the relevant mechanism, the effects of lipoic acid on the nerve cell apoptosis and the anti-apoptotic ERK signaling pathway were observed in this study. Lipoic acid $\mathrm{c}$ activates ERK signaling pathway by distinctly restraining nerve cell apoptosis and promoting $p$-ERK expression; this may be the crucial mechanism by which lipoic acid inhibits the expressions of Bax and caspase-3, but facilitates the Bcl-2 expression.

\section{CONCLUSION}

Lipoic acid inhibits nerve cell apoptosis in rats with Parkinson's disease by up-regulating ERK signaling pathway. Thus, it is a potential neuroprotective agent for the management of Parkinson's disease.

\section{DECLARATIONS}

\section{Conflict of Interest}

No conflict of interest associated with this work.

\section{Contribution of Authors}

The authors declare that this work was done by the authors named in this article and all liabilities pertaining to claims relating to the content of this article will be borne by them.

\section{Open Access}

This is an Open Access article that uses a funding model which does not charge readers or their institutions for access and distributed under the terms of the Creative Commons Attribution License (http://creativecommons.org/licenses/by/ 4.0) and the Budapest Open Access Initiative (http://www.budapestopenaccessinitiative.org/rea d), which permit unrestricted use, distribution, and reproduction in any medium, provided the original work is properly credited.

\section{REFERENCES}

1. Riederer $P$, Jellinger $K A$, Kolber $P$, Hipp $G$, SianHulsmann J, Kruger R. Lateralisation in Parkinson disease. Cell Tissue Res 2018; 373(1): 297-312.

2. Karimi-Moghadam A, Charsouei S, Bell B, Jabalameli MR. Parkinson Disease from Mendelian Forms to Genetic Susceptibility: New Molecular Insights into the Neurodegeneration Process. Cell Mol Neurobiol 2018; 38(6): 1153-1178.

3. Surmeier DJ, Obeso JA, Halliday GM. Selective neuronal vulnerability in Parkinson disease. Nat Rev Neurosci 2017; 18(2): 101-113.
4. Poewe W, Seppi K, Tanner CM, Halliday GM, Brundin P, Volkmann J, Schrag AE, Lang AE. Parkinson disease. Nat Rev Dis Primers 2017; 3: 17013.

5. Ffytche $D H$, Creese $B$, Politis $M$, Chaudhuri $K R$, Weintraub $D$, Ballard C, Aarsland D. The psychosis spectrum in Parkinson disease. Nat Rev Neurol 2017; 13(2): 81-95.

6. Armstrong RA. Visual Dysfunction in Parkinson's Disease. Int Rev Neurobiol 2017; 134: 921-946.

7. Schapira A, Chaudhuri KR, Jenner $P$. Non-motor features of Parkinson disease. Nat Rev Neurosci 2017; 18(7): 435-450.

8. Ren Q, Ma M, Yang J, Nonaka R, Yamaguchi A, Ishikawa KI, Kobayashi K, Murayama S, Hwang SH, Saiki S, Akamatsu W, Hattori N, Hammock BD, Hashimoto K. Soluble epoxide hydrolase plays a key role in the pathogenesis of Parkinson's disease. Proc Natl Acad Sci U S A 2018; 115(25): E5815-E5823.

9. Jang YC, Hwang DJ, Koo JH, Um HS, Lee NH, Yeom $D C$, Lee $Y$, Cho JY. Association of exercise-induced autophagy upregulation and apoptosis suppression with neuroprotection against pharmacologically induced Parkinson's disease. J Exerc Nutrition Biochem 2018; 22(1): 1-8.

10. Tian X, Chen WQ, Liu XL, Pi YP, Chen H. Efficacy and safety of oral zinc sulfate in the prevention of chemotherapy-induced oral mucositis: Protocol for a meta-analysis of randomized controlled trials. Medicine (Baltimore) 2018; 97(21): e10839.

11. Tolosa E, Botta-Orfila T, Morato X, Calatayud C, FerrerLorente R, Marti MJ, Fernandez M, Gaig C, Raya A, Consiglio A, Ezquerra $M$, Fernandez-Santiago $R$. MicroRNA alterations in iPSC-derived dopaminergic neurons from Parkinson disease patients. Neurobiol Aging 2018; 69: 283-291.

12. Lin $D$, Liang $Y$, Zheng $D$, Chen $Y$, Jing $X$, Lei $M$, Zeng $Z$, Zhou T, Wu X, Peng S, Huang K, Yang L, Xiao S, Liu J, Tao E. Novel biomolecular information in rotenoneinduced cellular model of Parkinson's disease. Gene 2018; 647: 244-260.

13. O'Neill E, Harkin A. Targeting the noradrenergic system for anti-inflammatory and neuroprotective effects: implications for Parkinson's disease. Neural Regen Res 2018; 13(8): 1332-1337.

14. Lee DJ, Dallapiazza RF, De Vloo P, Lozano AM. Current surgical treatments for Parkinson's disease and potential therapeutic targets. Neural Regen Res 2018; 13(8): 1342-1345.

15. Cerri S, Blandini F. Role of Autophagy in Parkinson's Disease. Curr Med Chem 2019; 26(20): 3702-3718.

16. Morgante L, Salemi G, Meneghini F, Di Rosa $A E$, Epifanio A, Grigoletto F, Ragonese P, Patti F, Reggio A, Di Perri R, Savettieri G. Parkinson disease survival: a population-based study. Arch Neurol 2000; 57(4): 507512.

17. Gloeckner CJ, Kinkl N, Schumacher A, Braun RJ, O'Neill $E$, Meitinger $T$, Kolch W, Prokisch $H$, Ueffing $M$. The Parkinson disease causing LRRK2 mutation I2020T is

Trop J Pharm Res, October 2021; 20(10): 2040 
associated with increased kinase activity. Hum $\mathrm{Mol}$ Genet 2006; 15(2): 223-232.

18. Kim YK, Kim HJ, Kwon CH, Kim JH, Woo JS, Jung JS, Kim JM. Role of ERK activation in cisplatin-induced apoptosis in OK renal epithelial cells. J Appl Toxicol 2005; 25(5): 374-382.

19. Liu Q, Hofmann PA. Protein phosphatase 2A-mediated cross-talk between p38 MAPK and ERK in apoptosis of cardiac myocytes. Am J Physiol Heart Circ Physiol 2004; 286(6): H2204-H2212.

20. Wang $C X$, Song JH, Song $D K$, Yong VW, Shuaib A, Hao C. Cyclin-dependent kinase-5 prevents neuronal apoptosis through ERK-mediated upregulation of $\mathrm{BCl}-2$. Cell Death Differ 2006; 13(7): 1203-1212. 